\title{
Downregulation of Endogenous Hydrogen Sulfide Pathway Is Involved in Mitochondrion-Related Endothelial Cell Apoptosis Induced by High Salt
}

\author{
Yanfang Zong, ${ }^{1}$ Yaqian Huang, ${ }^{1}$ Siyao Chen, ${ }^{1}$ Mingzhu Zhu, ${ }^{1}$ \\ Qinghua Chen, ${ }^{1}$ Shasha Feng, ${ }^{1}$ Yan Sun, ${ }^{1}$ Qingyou Zhang, ${ }^{1}$ Chaoshu Tang, ${ }^{2,3}$ \\ Junbao Du, ${ }^{1,2}$ and Hongfang Jin ${ }^{1}$ \\ ${ }^{1}$ Department of Pediatrics, Peking University First Hospital, Beijing 100034, China \\ ${ }^{2}$ Key Laboratory of Molecular Cardiology, Ministry of Education, Beijing 100191, China \\ ${ }^{3}$ Department of Physiology and Pathophysiology, Peking University Health Science Centre, Beijing 100191, China
}

Correspondence should be addressed to Hongfang Jin; jinhongfang51@126.com

Received 26 October 2014; Revised 25 December 2014; Accepted 26 December 2014

Academic Editor: Guangdong Yang

Copyright (C) 2015 Yanfang Zong et al. This is an open access article distributed under the Creative Commons Attribution License, which permits unrestricted use, distribution, and reproduction in any medium, provided the original work is properly cited.

Background. The study aimed to investigate whether endogenous $\mathrm{H}_{2} \mathrm{~S}$ pathway was involved in high-salt-stimulated mitochondriarelated vascular endothelial cell (VEC) apoptosis. Methods. Cultured human umbilical vein endothelial cells (HUVECs) were used in the study. $\mathrm{H}_{2} \mathrm{~S}$ content in the supernatant was detected. Western blot was used to detect expression of cystathionine gamma-lyase (CSE), cleaved-caspase-3, and mitochondrial and cytosolic cytochrome c (cytc). Fluorescent probes were used to quantitatively detect superoxide anion generation and measure the in situ superoxide anion generation in HUVEC. Mitochondrial membrane pore opening, mitochondrial membrane potential, and caspase- 9 activities were measured. The cell apoptosis was detected by cell death ELISA and TdT-mediated dUTP nick end labeling (TUNEL) methods. Results. High-salt treatment downregulated the endogenous VEC $\mathrm{H}_{2}$ S/CSE pathway, in association with increased generation of oxygen free radicals, decreased mitochondrial membrane potential, enhanced the opening of mitochondrial membrane permeability transition pore and leakage of mitochondrial cytc, activated cytoplasmic caspase- 9 and caspase- 3 and subsequently induced VEC apoptosis. However, supplementation of $\mathrm{H}_{2} \mathrm{~S}$ donor markedly inhibited VEC oxidative stress and mitochondria-related VEC apoptosis induced by high salt. Conclusion. $\mathrm{H}_{2} \mathrm{~S} / \mathrm{CSE}$ pathway is an important endogenous defensive system in endothelial cells antagonizing high-salt insult. The protective mechanisms for VEC damage might involve inhibiting oxidative stress and protecting mitochondrial injury.

\section{Introduction}

High-salt diet as an important risk factor of hypertension could interrupt body homeostasis, resulting in cardiovascular diseases and even life-threatening events. High-salt insult can promote the proliferation of vascular smooth muscle cells induced by angiotensin II, significantly increase blood pressure in salt-sensitive rats, and accelerate hypertensive process and the development of cardiovascular disease. Moreover, it can change small artery structures in normal-diet rats.

Numerous studies have been conducted to investigate the mechanisms for hypertension. Previous studies indicated that high-salt insult promoted hypertension in association with activating angiotensin-aldosterone system [1], damaging renal natriuresis function [2], enhancing sympathetic activity [3], increasing the extracellular capacity, and eventually leading to sodium and water retention [4]. In addition, high salt could destroy the transfer passage of paraventricular nucleus Gai-protein gating signals [5]. However, the mechanisms for high-salt-induced hypertension remain unclear. Vascular endothelial cell serves as a junction of blood flow and vessel wall. Maintenance of vascular endothelium integrity is essential for smooth blood flow, which plays an important role in maintaining vascular homeostasis [6]. Endothelial dysfunction is the initial cause of the onset and development of a variety of cardiovascular diseases [7]. Importantly, vascular 
endothelium dysfunction plays a key role in the pathogenesis of salt-sensitive hypertension, while high-salt stimulation could damage vascular endothelial function [8]. High salt led to endothelial cell cortex sclerosis via compromising epithelial sodium channels [9] and contributing to intracellular edema and mitochondrion swelling [10] while the mechanisms for intracellular structural changes and endothelial dysfunction are unidentified. In normotensive rats, highsalt diet increased production of reactive oxygen species in striated muscle and superior mesenteric arteries, activating the oxidative stress system $[11,12]$. Therefore, we speculated that high-salt-induced oxidative damage might be involved in the development of cell damage induced by high salt. $\mathrm{H}_{2} \mathrm{~S}$ is known as a gas with rotten egg stink and toxicity. Recent studies suggest that endogenous $\mathrm{H}_{2} \mathrm{~S}$ exerts biological effects and acts as a novel gaseous signal molecule [13-19]. Several studies indicated that $\mathrm{H}_{2} \mathrm{~S} / \mathrm{CSE}$ pathway was downregulated in the development of hypertension, while $\mathrm{H}_{2} \mathrm{~S}$ supplementation could significantly lower blood pressure and reverse aortic remodeling $[20,21]$. It was also implied that $\mathrm{H}_{2} \mathrm{~S}$ could protect human umbilical vein endothelial cells (HUVECs) via antagonizing oxidative stress-related pathways [22]. Hence, we proposed a hypothesis that downregulation of endogenous $\mathrm{H}_{2} \mathrm{~S} / \mathrm{CSE}$ might be involved in mitochondrion-related endothelial cell injury induced by high-salt exposure.

Therefore, the present study was undertaken to explore the possible effects of endogenous $\mathrm{H}_{2} \mathrm{~S}$ on endothelial apoptosis under high-salt stimulation and its mechanisms.

\section{Materials and Methods}

2.1. Cell Culture. HUVECs were purchased from Lifeline Cell Technology, USA. The 3-7 generations of HUVEC were used in this experiment. HUVECs were cultured in the medium which was supplemented with $0.2 \%$ FBS, $0.1 \%$ rh VEGF, $0.1 \%$ rh IGF-1, 0.1\% rh FGF-b, 0.1\% ascorbic acid, 0.1\% rh EGF, $0.1 \%$ heparin, $0.1 \%$ Hydrocort, and 5\% L-glutamine (Lifeline Cell Technology, USA) in an incubator containing 5\% $\mathrm{CO}_{2}$ at constant temperature of $37^{\circ} \mathrm{C}$. The cells were cultured in exogenous growth factors-free medium and synchronized for $12 \mathrm{~h}$ before each experiment. The concentration of sodium in the synchronization medium was $137 \pm 1.0 \mathrm{mmol} / \mathrm{L}$. Sodium chloride (Sinopharm, Shanghai, China) was added to culture medium at different concentrations including $150 \mathrm{mmol} / \mathrm{L}$, $200 \mathrm{mmol} / \mathrm{L}$, and $250 \mathrm{mmol} / \mathrm{L}$.

\subsection{Measurement of Endogenous $\mathrm{H}_{2} \mathrm{~S}$ Content in HUVEC.} Endogenous $\mathrm{H}_{2} \mathrm{~S}$ in cells was measured using a fluorescent probe (provided by Professor Xinjing Tang, Peking University Health Science Centre, China) as described previously [23]. The culture supernatant was collected to test $\mathrm{H}_{2} \mathrm{~S}$ levels in HUVEC. Then, the slides were washed with PBS $(0.01 \mathrm{~mol} / \mathrm{L})$ for three times and fixed in prewarmed $4 \%$ paraformaldehyde at room temperature for $20 \mathrm{~min}$. After washing with PBS three times, the slides were stained in the working liquid of fluorescent probe for $30 \mathrm{~min}$ at $37^{\circ} \mathrm{C}$. The slides were mounted by antifade solution (Applygen, Beijing, China) after washing with PBS. Then, the slides were detected as blue fluorescent by laser confocal scanning microscope. The concentration of $\mathrm{H}_{2} \mathrm{~S}$ in culture supernatant was detected by the free radical analyzer TBR4100 (World Precision Instruments, USA). First, the ISO- $\mathrm{H}_{2} \mathrm{~S}-100$ sensor was polarized with PBS buffer solution ( $\mathrm{pH} 7.2,0.05 \mathrm{~mol} / \mathrm{L}$ ) to achieve a stable baseline current (usually between 100 and 2000 pA). Then, the sensor was calibrated by the standards, in which the concentration of $\mathrm{H}_{2} \mathrm{~S}$ was $0.5 \mu \mathrm{mol} / \mathrm{L}, 1 \mu \mathrm{mol} / \mathrm{L}, 2 \mu \mathrm{mol} / \mathrm{L}, 4 \mu \mathrm{mol} / \mathrm{L}, 8 \mu \mathrm{mol} / \mathrm{L}$, and $16 \mu \mathrm{mol} / \mathrm{L}$, respectively. The current output jumped rapidly after each sample and then plateaus. As soon as it reached a plateau, the next sample was injected. The reduction difference between the peak and baseline was recorded (pA). Then, the calibration curve was constructed by plotting the reduction difference ( $\mathrm{pA}$ ) against the concentration $(\mu \mathrm{mol} / \mathrm{L})$ of $\mathrm{H}_{2} \mathrm{~S}$. The sensor tip was immersed into each cultural supernatant sample in about $10-15 \mathrm{~mm}$ deep, and the concentration of $\mathrm{H}_{2} \mathrm{~S}$ was calculated via the equation.

2.3. Western Blotting Analysis. Expressions of CSE, cytochrome c (cytc), and caspase- 3 as well as cleaved-caspase- 3 in HUVEC were detected by western blot. The total protein of HUVEC was extracted using ice-cold cell lysis buffer containing $50 \mathrm{mmol} / \mathrm{L}$ Tris- $\mathrm{HCl}, 150 \mathrm{mmol} / \mathrm{L} \mathrm{NaCl}, 1 \mathrm{mmol} / \mathrm{L}$ PMSF, $1 \mathrm{mmol} / \mathrm{L}$ EDTA, $5 \mu \mathrm{g} / \mathrm{mL}$ aprotinin, $5 \mu \mathrm{g} / \mathrm{mL}$ leupeptin, $1 \%$ Triton X-100, 1\% sodium deoxycholate, and $0.1 \%$ SDS. The cells were washed with ice-cold PBS for three times, soaked in ice-cold lysis buffer for $30 \mathrm{~min}$, and scraped off. Cell lysate was subsequently centrifuged at $12000 \mathrm{~g}$ for $10 \mathrm{~min}$ at $4^{\circ} \mathrm{C}$, and supernatant was reserved. Protein concentration was detected using BCA method. Equal amount of protein sample $(60 \mu \mathrm{g})$ was loaded, and SDS-PAGE electrophoresis of $10 \%$ or $12 \%$ separation gel was conducted. The separated proteins were transferred onto a nitrocellulose membrane for $2 \mathrm{~h}$ at $200 \mathrm{~mA}$ after electrophoresis. The membranes were blocked with $5 \%$ dried skimmed milk for $1 \mathrm{~h}$. Then, the primary antibodies CSE (Sigma, USA) (dilution $1: 200$ ), cytc (Santa Cruz, USA) (dilution 1: 200), caspase-3 (Cell Signaling Technology, USA) (dilution 1:1000), and cleaved-caspase3 (Cell Signaling Technology, USA) (dilution 1:200) were added, respectively, and incubated at $4^{\circ} \mathrm{C}$ overnight. The second antibody was incubated for $1 \mathrm{~h}$ at room temperature after washing. LumiGLO chemiluminescence reagent was used and exposed to films. Quantification of blots was analyzed using an AlphaImager (San Leandro, CA, USA).

2.4. Preparation of Mitochondrial Protein. Separation of mitochondrion and cytoplasm was conducted using Mitochondria Isolation Kit (Applygen, Beijing, China). The HUVECs were mixed thoroughly with Mito solution after centrifugation at $800 \mathrm{~g}$ for $5 \mathrm{~min}$, at $4^{\circ} \mathrm{C}$. The supernatant was collected in a fresh tube on ice after centrifuging at $800 \mathrm{~g}$ for $5 \mathrm{~min}$, at $4^{\circ} \mathrm{C}$ twice. Supernatant containing cytoplasm was then collected after centrifuging at $10000 \mathrm{~g}$ for $20 \mathrm{~min}$, at $4^{\circ} \mathrm{C}$, while precipitate containing mitochondria was processed for further centrifugation. The precipitate was washed with Mito solution and centrifugated at $12000 \mathrm{~g}$ for $10 \mathrm{~min}$, at $4^{\circ} \mathrm{C}$. The sedimentation was dissolved in Mito solution. 
2.5. Detection of Superoxide Anion in HUVEC by Dihydroethidium (DHE) and CellROX Green Reagent. DHE (Beyotime, Shanghai, China) was used to detect superoxide anion in HUVEC. The medium covering the cells was changed after washing three times with PBS. Then, the cells were incubated with DHE probes for $30 \mathrm{~min}$ at $37^{\circ} \mathrm{C}$, avoiding light exposure. Subsequently, the cells were mounted in new cultural medium for observation under a fluorescence microscope. Moreover, CellROX Green Reagent (Thermo Fisher, MA, USA) was used to quantify the generation of superoxide anion in HUVEC. HUVECs were plated in a 96-well plate. CellROX Green Reagent at a final concentration of $5 \mu \mathrm{mol} / \mathrm{L}$ was added in the medium and incubated with cells at $37^{\circ} \mathrm{C}$ for $60 \mathrm{~min}$. The cells were then washed with PBS and analyzed on Fluoroskan Ascent Fluorometer (Thermo Fisher, MA, USA). Fluorescence intensity was analyzed at the excitation/ emission wavelengths of $488 / 520 \mathrm{~nm}$.

2.6. Detection of Mitochondrial Superoxide Anion in HUVEC by MitoSOX Reagent. MitoSOX Red Mitochondrial Superoxide Indicator (Thermo Fisher, MA, USA) was used to detect the generation of mitochondrial superoxide anion in HUVEC and MitoTracker Green FM (Thermo Fisher, MA, USA) was used to label mitochondria. The HUVEC on slides were covered with MitoSOX $(5 \mu \mathrm{mol} / \mathrm{L})$ and MitoTracker probes $(100 \mathrm{nmol} / \mathrm{L})$ after washing with PBS. The slides were incubated for $20 \mathrm{~min}$ at $37^{\circ} \mathrm{C}$, avoiding light. Then, the HUVECs were fixed in prewarmed $4 \%$ paraformaldehyde at room temperature for $15 \mathrm{~min}$ after washing with warm PBS for three times. The slides were mounted by antifade solution (Applygen, Beijing, China) after washing with PBS. Cells on the slides were detected by a laser scanning confocal microscope. Red fluorescence indicated mitochondrial superoxide anion and green fluorescence indicated labeled mitochondria.

2.7. Detection of Mitochondrial Permeability Transition Pore (MPTP) Opening in HUVEC. Cell MPTP Assay Kit (Genmed, Shanghai, China) was used to test the MPTP opening in HUVEC. Experiment rationale was that calcein-AM could gather in mitochondrion presenting green fluorescent staining, whereas, being released into the cytoplasm via the opening of MPTP, fluorescent quenching could occur. Culture medium was discarded and slides were rinsed gently with cleaning solution. Slides were subsequently incubated with staining working solution for $30 \mathrm{~min}$ at $37^{\circ} \mathrm{C}$, protecting from light. $4 \%$ paraformaldehyde was used to fix the cells for $15 \mathrm{~min}$ after rinsing for three times with cleaning solution. Finally, the slides were mounted with antifade solution (Applygen, Beijing, China) after washing with PBS three times and were immediately examined using a laser confocal microscope.

2.8. Measurement of Mitochondrial Membrane Potential in HUVEC. Mitochondrial membrane potential in HUVEC was measured by Mitochondrial Membrane Potential Assay Kit with JC-1 (Beyotime, Shanghai, China). When mitochondrial membrane potential is high in living cells, JC-1 accumulates in matrix in the form J-aggregates presenting red fluorescence; while mitochondrial membrane potential is low in apoptotic cells, JC-1 cannot aggregate, and the JC1 monomer presents green fluorescence. Decreased mitochondrial membrane potential suggests apoptosis. Briefly, JC-1 working solution and cell medium were mixed at the ratio of $1: 1$. Then, the slides seeded with HUVEC were incubated with the mixture for $20 \mathrm{~min}$ at $37^{\circ} \mathrm{C}$ in the dark. The cells were fixed in prewarmed $4 \%$ paraformaldehyde at room temperature for $20 \mathrm{~min}$ after washing with ice-cold JC1 buffer solution twice. After washing three times with PBS, the antifade solution (Applygen, Beijing, China) was used to mount the slides. Analysis was conducted immediately using a laser confocal scanning microscope.

2.9. In Situ and Quantitative Measurement of Caspase-9 Activity Assay in HUVEC. Change of in situ caspase-9 activity in HUVEC was detected by living cells caspase- 9 activity fluorescence staining kit (Genmed, Shanghai, China). Briefly, after washing twice with PBS buffer, the cells on glass slide were incubated with fluorescence probe FITC-LEHD-FMK, a FITC labeling inhibitor of caspase-9, in room temperature for $30 \mathrm{~min} .4 \%$ paraformaldehyde was used to fix the cells in room temperature for $30 \mathrm{~min}$ after washing three times with PBS buffer. Then the antifade solution was used to mount the slides. Observations were made immediately under a laser confocal scanning microscope.

Change of caspase- 9 activity in HUVEC was quantified using cell caspase-9 colorimetric activity kit (Genmed, Shanghai, China). The assay was based on spectrophotometric detection of the chromophore p-nitroaniline (pNA) cleavage by caspase- 9 from the labeled substrate Ac-LEHDpNA. The free pNA was quantified using a microtiter plate reader at $405 \mathrm{~nm}$. Briefly, after washing twice with PBS buffer, the cells were incubated with lysis buffer on ice for $30 \mathrm{~min}$. The cells were subsequently scraped off carefully and centrifuged for $5 \mathrm{~min}$ at $16000 \mathrm{~g}$ in a microcentrifuge. The supernatant was collected in a fresh tube on ice. The BCA method was used for protein concentration determination. Then $50 \mu \mathrm{g}$ sample and substrate buffer were put into 96well plate in order and incubated for $90 \mathrm{~min}$ at $37^{\circ} \mathrm{C}$. Finally, samples were read in a microtiter plate reader (Bio-Rad, Hercules, CA, USA) at $405 \mathrm{~nm}$.

2.10. In Situ and Quantitative Detection of Apoptosis in HUVEC by Using TdT-Mediated dUTP Nick End Labeling (TUNEL) Assay and ELISA Assay. In situ apoptosis of HUVEC was detected with in situ Cell Death Detection Kit, Fluorescein (Roche, Mannheim, Germany) in accordance with the instructions of the manufacturer. Briefly, the cells on slides were washed for three times with PBS. Then, the slides were covered with TUNEL reaction mixture and incubated for $60 \mathrm{~min}$ at $37^{\circ} \mathrm{C}$ in dark. The cells were fixed in prewarmed $4 \%$ paraformaldehyde at room temperature for 15 min after washing with PBS. Then, the antifade solution was used to mount the slides after washing three times with PBS, and the slides were immediately transferred for analysis under a laser confocal scanning microscope. Moreover, the quantitative detection of DNA fragments in HUVEC was 

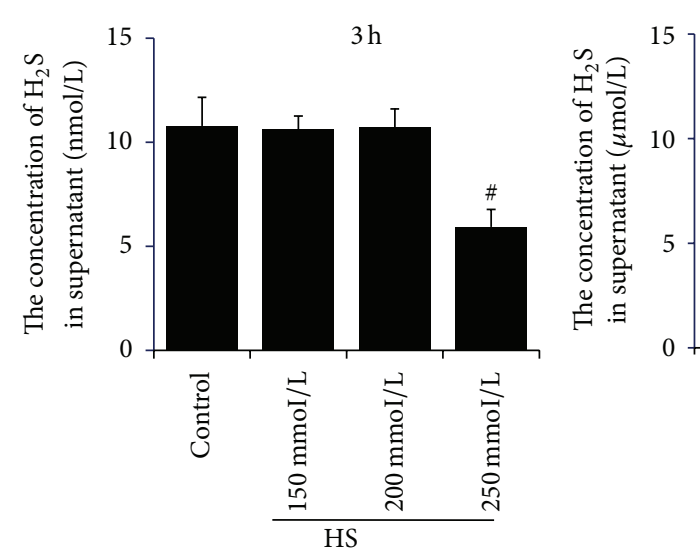

$6 \mathrm{~h}$

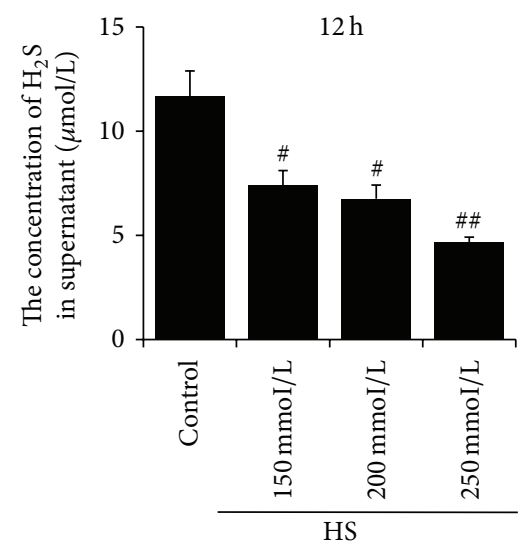

(a)
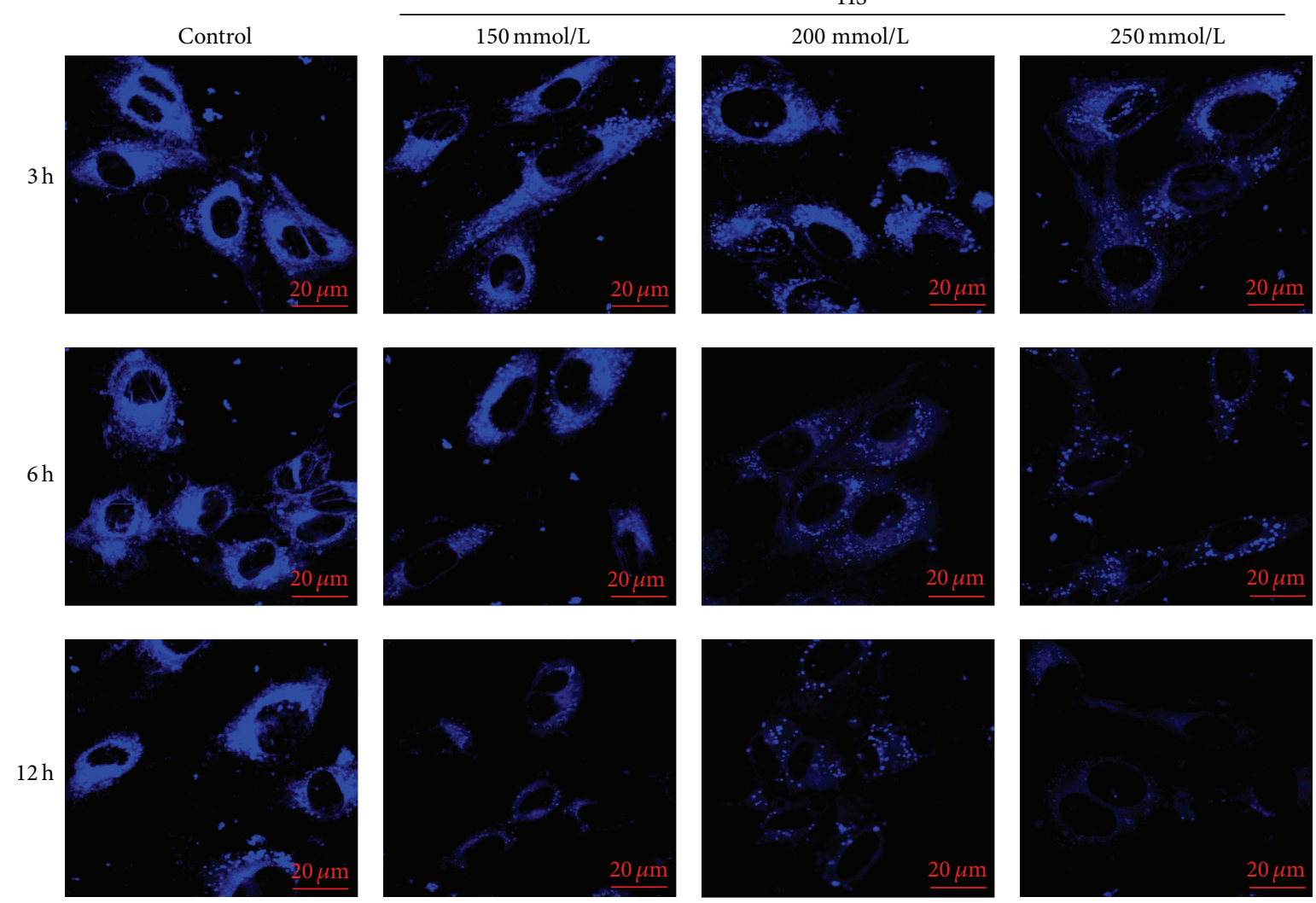

(b)

FIgure 1: Continued. 
$3 \mathrm{~h}$

$$
\text { CSE }
$$

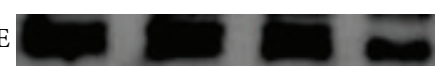

GAPDH

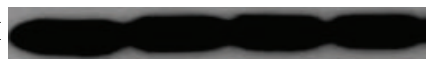

GAPDH

\begin{abstract}
CSE
\end{abstract}
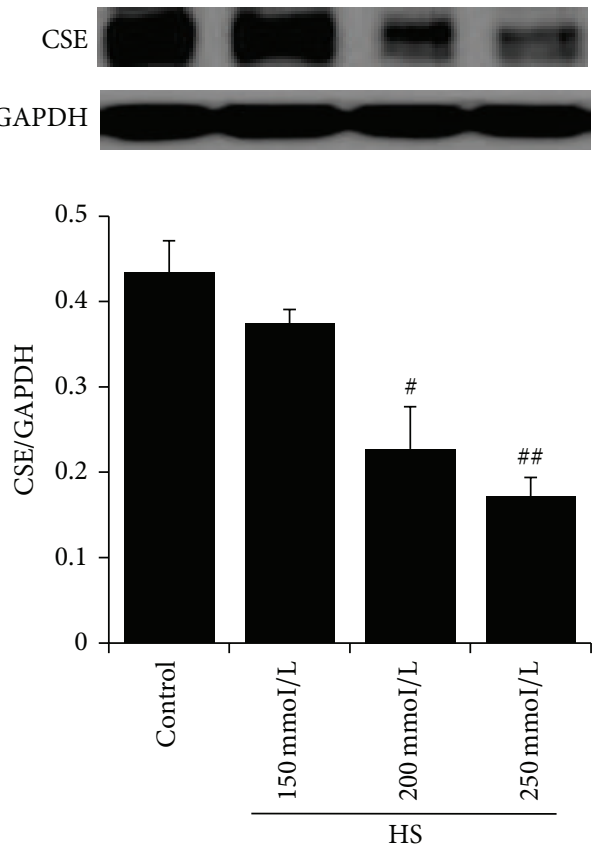

(c)

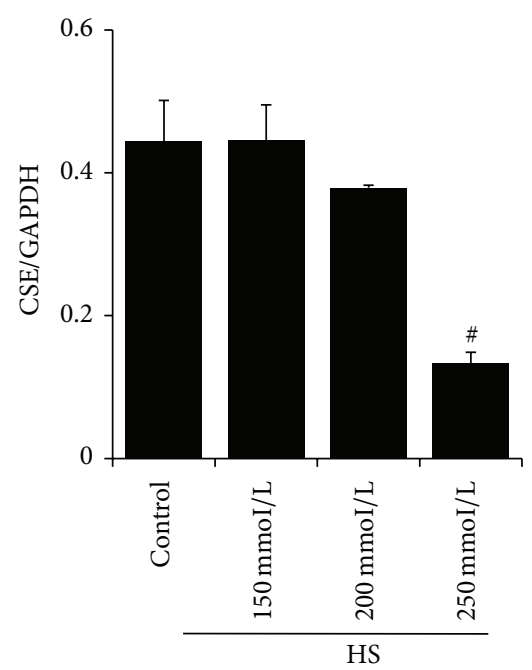

$12 \mathrm{~h}$
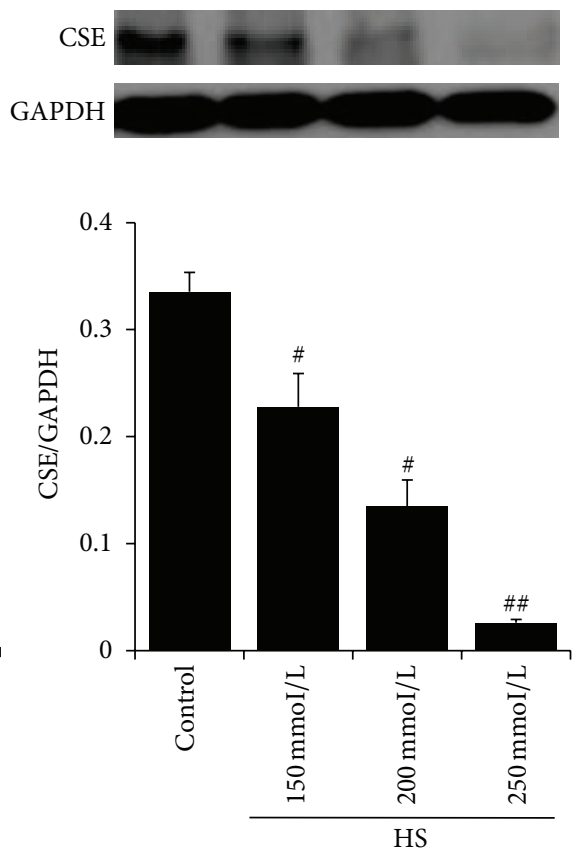

FIGURE 1: Changes in endogenous $\mathrm{H}_{2} \mathrm{~S}$ pathway in human umbilical vein endothelial cells (HUVECs). (a) The concentration of endogenous $\mathrm{H}_{2} \mathrm{~S}$ in supernatant detected by the free radical analyzer TBR4100; (b) the production of endogenous $\mathrm{H}_{2} \mathrm{~S}$ in $\mathrm{HUVEC}_{2}$ determined by $\mathrm{H}_{2} \mathrm{~S}$ fluorescent probe; and (c) CSE protein expression in HUVEC analyzed by western blotting. Control: the concentration of sodium was $137 \mathrm{mmol} / \mathrm{L}$. HS: high salt; the concentration of sodium was $150 \mathrm{mmol} / \mathrm{L}, 200 \mathrm{mmol} / \mathrm{L}$, and $250 \mathrm{mmol} / \mathrm{L}$, respectively. The scale in (b) represented $20 \mu \mathrm{m} .{ }^{\# \#} P<0.01 ;{ }^{\#} P<0.05$ versus control group.

measured by Cell Death Detection ELISA ${ }^{\text {PLUS }}$ Kit (Roche, Mannheim, Germany) according to the suggested protocol of the manufacturer. The assay is based on a quantitative sandwich-enzyme-immunoassay principle using mouse monoclonal antibodies directed against DNA and histones, respectively. This allows the specific determination of monoand oligonucleosomes in the cytoplasmatic fraction of cell lysates. Briefly, the cell lysate was added into a streptavidincoated microplate. A mixture of anti-histone-biotin and antiDNA-POD was added and incubated. During the incubation period, the antibody-nucleosome complexes were bound to the microplate by the streptavidin. After a washing step, the unbound components were removed. The amount of nucleosomes by the POD retained in the immunocomplex was quantitatively determined by a microtiter plate reader (Bio-Rad, CA, USA) at $405 \mathrm{~nm}$.

2.11. Statistical Analysis. Data are described as mean \pm SE. SPSS 13 (SPSS Software, Inc., Chicago, IL, USA) was used for data analysis. Independent-samples $t$-test or one-way ANOVA followed by either LSD test was conducted and $P<$ 0.05 was considered statistically significant.

\section{Results}

3.1. The Endogenous $\mathrm{H}_{2} \mathrm{~S}$ Pathway Was Downregulated in High-Salt- (HS-) Stimulated HUVEC. Compared with control group, $\mathrm{H}_{2} \mathrm{~S}$ synthesis in $\mathrm{HUVEC}$ was significantly reduced with prolonged sodium chloride $(\mathrm{NaCl})$ incubation. After the treatment with $250 \mathrm{mmol} / \mathrm{L} \mathrm{NaCl}$ medium for $3 \mathrm{~h}$, $\mathrm{H}_{2} \mathrm{~S}$ content in the culture supernatant of HUVEC was significantly decreased (Figure 1(a)), and the fluorescence of $\mathrm{H}_{2} \mathrm{~S}$ probes weakened (Figure 1(b)). $\mathrm{H}_{2} \mathrm{~S}$ content in the culture supernatant was significantly decreased after incubation with $200 \mathrm{mmol} / \mathrm{L}$ and $250 \mathrm{mmol} / \mathrm{L} \mathrm{NaCl}$ medium for $6 \mathrm{~h}$, respectively, with parallel decrease of the $\mathrm{H}_{2} \mathrm{~S}$ probe fluorescence in HUVECs (Figure 1(b)). Moreover, $12 \mathrm{~h}$ incubation with $150 \mathrm{mmol} / \mathrm{L}, 200 \mathrm{mmol} / \mathrm{L}$, and $250 \mathrm{mmol} / \mathrm{L}$ $\mathrm{NaCl}$ medium demonstrated a significantly decreased $\mathrm{H}_{2} \mathrm{~S}$ content in HUVEC culture supernatant (Figure 1(a)) as well as reduced $\mathrm{H}_{2} \mathrm{~S}$ probe fluorescence (Figure $1(\mathrm{~b})$ ). The results of CSE protein expression in HUVEC were consistent with the variation trend of $\mathrm{H}_{2} \mathrm{~S}$ content (Figure $1(\mathrm{c})$ ).

3.2. $\mathrm{H}_{2} \mathrm{~S}$ Inhibited Superoxide Anion Generation in High-SaltInduced HUVEC. Compared with control group, the superoxide anion generation in HUVEC of HS group represented by both DHE staining image and fluorescence quantification with CellROX Green Reagent on fluorometer was significantly increased (Figures 2(a) and 2(b)). However, when pretreated with NaHS, the superoxide anion generation in high-salt-induced HUVEC was decreased markedly (Figures 2(a) and 2(b)). Furthermore, the change of superoxide anion generation in mitochondria of HUVEC detected by MitoSOX probe was in accordance with the change of superoxide anion generation in whole HUVEC (Figure 2(c)). 


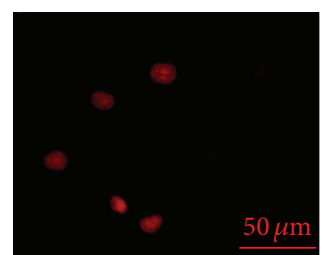

Control

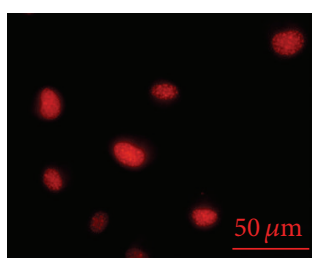

HS

(a)
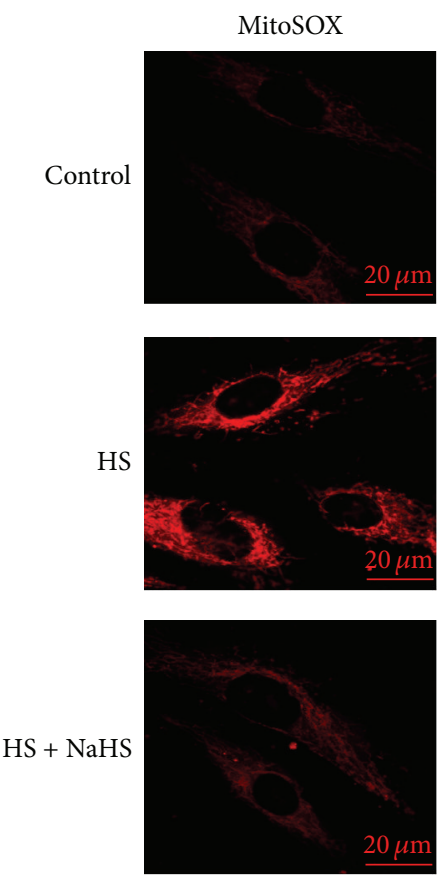

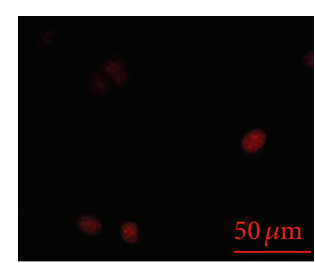

$\mathrm{HS}+\mathrm{NaHS}$

MitoTracker
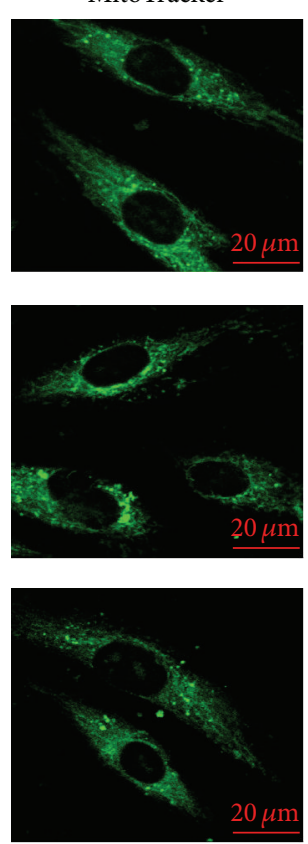

(c)

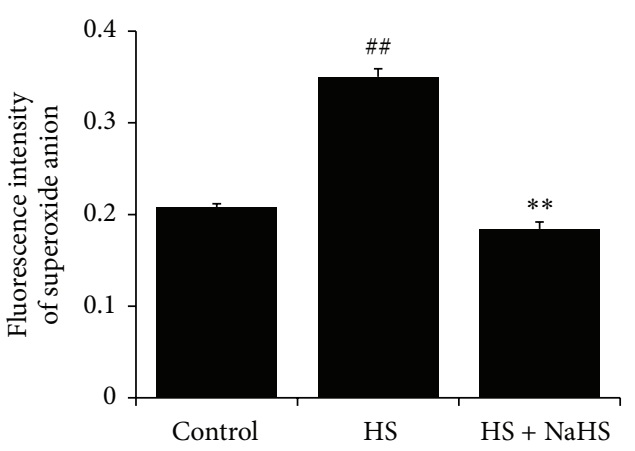

(b)
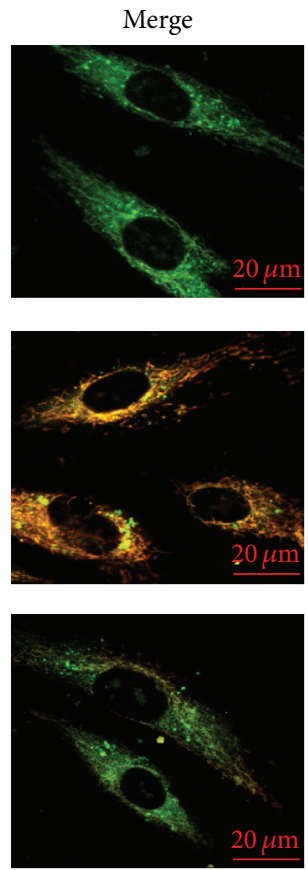

FIgURE 2: Changes in superoxide anion generation in human umbilical vein endothelial cells (HUVECs). (a) Fluorescent micrographs of superoxide anion generation in HUVEC detected by DHE probes. Red fluorescence indicates levels of superoxide anion generation in HUVEC; (b) quantification analysis of fluorescent intensity of superoxide anion generation in HUVEC detected by CellROX Green Reagent on Fluoroskan Ascent Fluorometer; (c) superoxide anion generation in HUVEC mitochondria detected by MitoSOX probes. Control: the cell treated with $137 \mathrm{mmol} / \mathrm{L}$ sodium. HS: high salt, the cell treated with $200 \mathrm{mmol} / \mathrm{L}$ sodium for $6 \mathrm{~h}$. HS + NaHS: the cell pretreated with $200 \mu \mathrm{mol} / \mathrm{L}$ NaHS for $30 \mathrm{~min}$ following $200 \mathrm{mmol} / \mathrm{L}$ sodium for $6 \mathrm{~h} .{ }^{\# \#} \mathrm{P}<0.01$ versus control group; ${ }^{* *} P<0.01$ versus HS group.

3.3. $\mathrm{H}_{2} \mathrm{~S}$ Inhibited Mitochondrial Dysfunction in High-SaltInduced HUVEC. In HS group, the mitochondrial membrane potential was significantly reduced (Figure 3(a)) and mitochondrial permeability transition pore significantly opened (Figure $3(\mathrm{~b})$ ) relative to that of the control group, whereas $\mathrm{H}_{2} \mathrm{~S}$ donor increased mitochondrial membrane potential (Figure 3(a)) and closed mitochondria permeability transition pore in HS-treated HUVEC (Figure 3(b)).

3.4. $\mathrm{H}_{2} \mathrm{~S}$ Antagonized High-Salt-Induced Release of Cytc from Mitochondria into Cytoplasm in HUVEC. Western blot results showed no significant difference of the total cytc among different groups. Interestingly, compared with control group, high-salt treatment significantly downregulated cytc protein expression in mitochondria of HUVEC $(P<0.05)$ and markedly increased cytoplasmic cytc $(P<0.01)$ (Figure 4), whereas, in the presence of NaHS, the cytoplasmic cytc protein expression was profoundly downregulated $(P<$ $0.01)$ and mitochondria cytc was upregulated $(P<0.01)$ (Figure 4) in HS + NaHS-treated HUVEC as compared with that of HS-treated HUVEC.

\section{5. $\mathrm{H}_{2} \mathrm{~S}$ Inhibited Caspase-9 Activation in High-Salt-Treated} HUVEC. Compared with the control group, incubation with high salt for $6 \mathrm{~h}$ markedly enhanced the green fluorescence indicating caspase- 9 activities in HUVEC and semiquantitative analysis suggested profoundly increased caspase- 9 

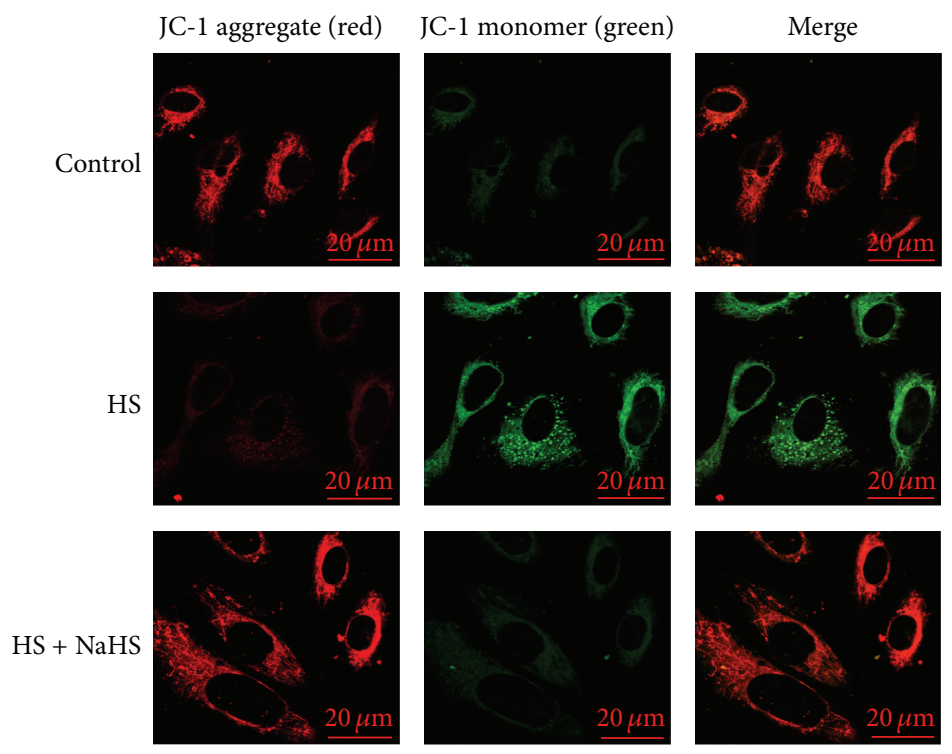

(a)

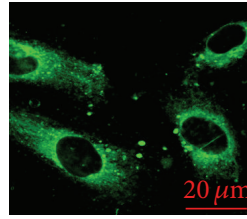

Control

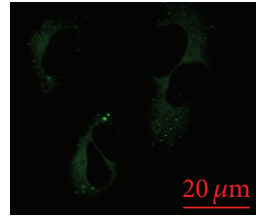

HS

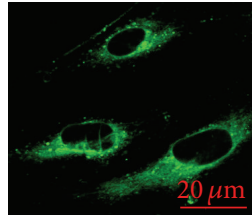

$\mathrm{HS}+\mathrm{NaHS}$

(b)

FIGURE 3: Changes in mitochondrial membrane potential and mitochondrial permeability transition pore (MPTP) opening in human umbilical vein endothelial cells (HUVECs). (a) Change of mitochondrial membrane potential detected by JC-1 fluorescent probe and examined by laser confocal microscope, with red fluorescence presenting JC-1 aggregate and green JC-1 monomer. (b) Changes of MPTP opening in HUVEC detected by calcein-AM as a fluorescence indicator by laser confocal microscopy. The green fluorescence quenching represented MPTP opening. Control: the cell treated with $137 \mathrm{mmol} / \mathrm{L}$ sodium. HS: high salt, the cell treated with $200 \mathrm{mmol} / \mathrm{L}$ sodium for $6 \mathrm{~h}$. HS + NaHS: the cell pretreated with $200 \mu \mathrm{mol} / \mathrm{L} \mathrm{NaHS}$ for $30 \mathrm{~min}$ following $200 \mathrm{mmol} / \mathrm{L}$ sodium for $6 \mathrm{~h}$.

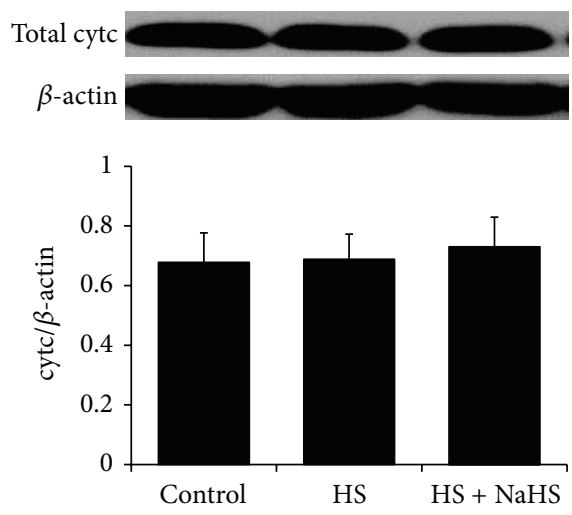

(a)
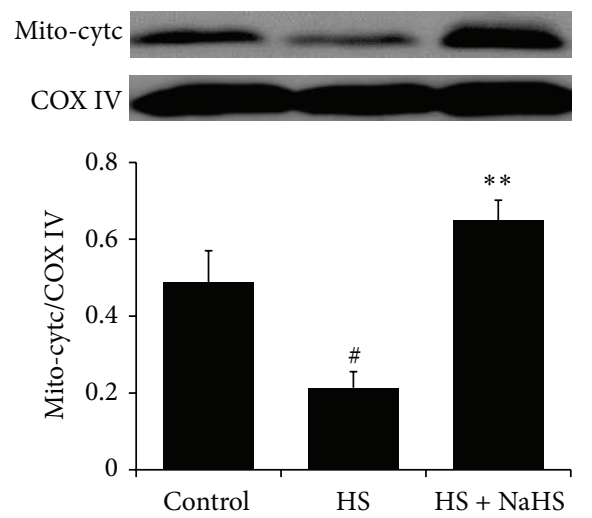

(b)
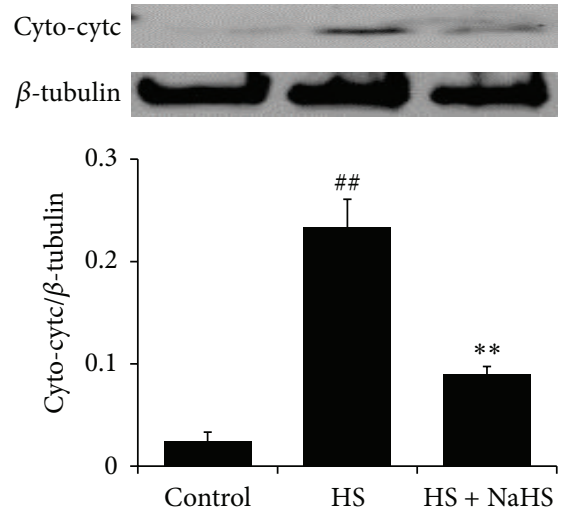

(c)

FIGURE 4: Cytochrome c (cytc) protein expression and distribution in human umbilical vein endothelial cells (HUVECs). Control: the cell treated with $137 \mathrm{mmol} / \mathrm{L}$ sodium. HS: high salt, the cell treated with $200 \mathrm{mmol} / \mathrm{L}$ sodium for $6 \mathrm{~h}$. HS + NaHS: the cell pretreated with $200 \mu \mathrm{mol} / \mathrm{L}$ NaHS for $30 \mathrm{~min}$ following $200 \mathrm{mmol} / \mathrm{L}$ sodium for $6 \mathrm{~h} .{ }^{\# \#} P<0.01,{ }^{\#} P<0.05$ versus control group; ${ }^{* *} P<0.01$ versus HS group. 

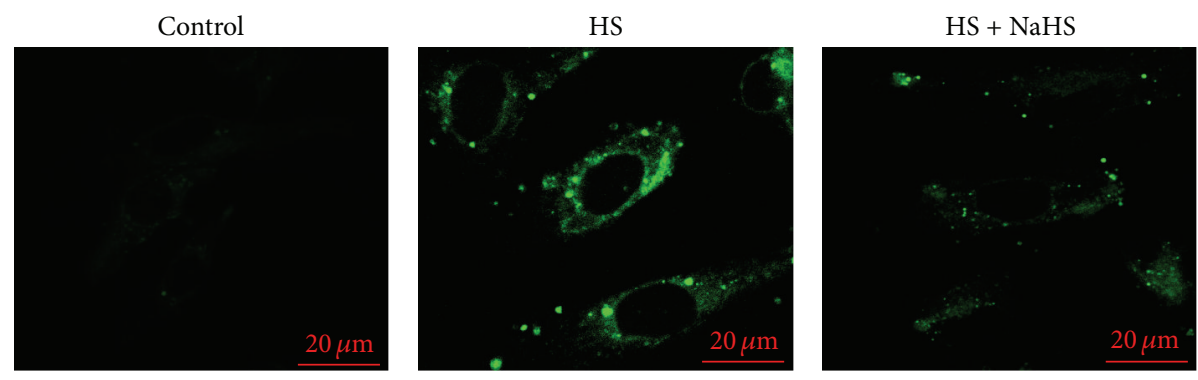

(a)

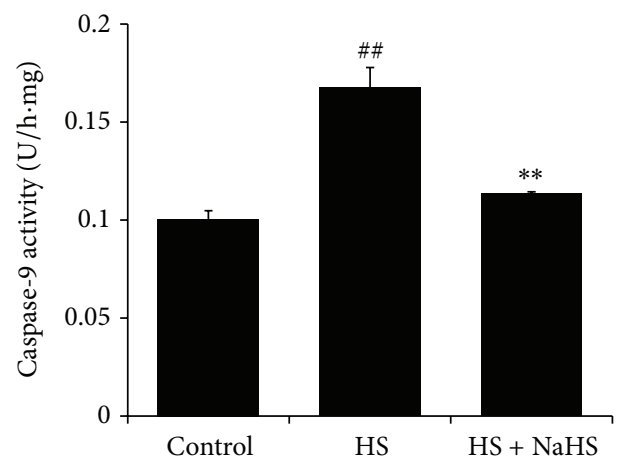

(b)

FIGURE 5: Caspase-9 activities in human umbilical vein endothelial cells (HUVECs). (a) Caspase-9 activities in HUVEC detected by living cells caspase-9 fluorescence staining kit. (b) Quantitative analysis of caspase-9 activities in HUVEC. Control: the cell treated with $137 \mathrm{mmol} / \mathrm{L}$ sodium. HS: high salt, the cell treated with $200 \mathrm{mmol} / \mathrm{L}$ sodium for $6 \mathrm{~h}$. HS + NaHS: the cell pretreated with $200 \mu \mathrm{mol} / \mathrm{L}$ NaHS for $30 \mathrm{~min}$ following $200 \mathrm{mmol} / \mathrm{L}$ sodium for $6 \mathrm{~h} .{ }^{\# \#} P<0.01$ versus control group; ${ }^{* *} P<0.01$ versus HS group.

activity (Figure 5), while $\mathrm{H}_{2} \mathrm{~S}$ administration reversed the high-salt-induced caspase-9 activities (Figure 5).

3.6. $\mathrm{H}_{2}$ S Reversed HS-Induced HUVEC Apoptosis. After incubation with high salt $(200 \mathrm{mmol} / \mathrm{L})$ for $6 \mathrm{~h}$, the ratio of cleaved-caspase-3/caspase-3 in HUVECs was markedly increased $(P<0.01)$ (Figure 6(a)), the amount of nucleosomes in the HUVEC lysate representing DNA fragmentation was increased $(P<0.01)$ (Figure 6(b)), and the green fluorescence intensity in the nuclei of TUNEL-positive HUVECs was augmented (Figure 6(c)). Interestingly, $\mathrm{H}_{2} \mathrm{~S}$ donor inhibited caspase-3 activation, and DNA fragmentation in HUVECs was treated with high salt $(P$ all $<0.01)$ (Figures 6(a) and 6(b)) and weakened the green fluorescence intensity in the nuclei of TUNEL-positive HUVECs (Figure 6(c)).

\section{Discussion}

High-salt diet is an important risk factor associated with hypertension. Recently, several studies have focused on investigating the direct impact of high salt on blood vessels. Liu et al. [24] found that high salt could promote the proliferation of vascular smooth muscle cells induced by angiotensin II. A recent study by Dmitrieva and Burg [25] proved that high salt might increase the secretion of von Willebrand factor (vWF) in vascular endothelial cells, resulting in hypercoagulability and thrombosis. Vascular endothelial cells serve as the primary barrier maintaining vascular function and structural stability. In the present study, we found that increased concentration of extracellular $\mathrm{NaCl}$ promoted caspase- 3 activities and apoptosis in endothelial cells as demonstrated by TUNEL assay, confirming that high salt could stimulate endothelial cell apoptosis. Then, subsequently, the possible mechanism involved was examined.

The cardiovascular protective effects of endogenous $\mathrm{H}_{2} \mathrm{~S}$ have been widely reported. Yang et al. [20] discovered that $\mathrm{H}_{2} \mathrm{~S}$ generated by vascular endothelial cells played an important regulatory role in maintaining vascular structure and function and CSE deficiency was involved in the abolished endothelium-dependent vasodilation and hypertention in mutant mice. Shen et al. [22] reported $\mathrm{H}_{2} \mathrm{~S}$ encouraged the proliferation and migration of endothelial cells and played a protective role in vascular endothelial cells. In our present study, $\mathrm{H}_{2} \mathrm{~S}$ content in both vascular endothelia and culture supernatant showed a time-dependent reduction after highsalt treatment in addition to downregulated expression of CSE, a key enzyme for $\mathrm{H}_{2} \mathrm{~S}$ synthesis. Nevertheless, supplementing $\mathrm{H}_{2} \mathrm{~S}$ donor markedly inhibited endothelial cell apoptosis induced by high salt, suggesting that high-salt-induced downregulation of endogenous $\mathrm{H}_{2} \mathrm{~S}$ pathway resulted in inadequate protective effects of $\mathrm{H}_{2} \mathrm{~S}$ on vascular endothelial cells, which might be one of the mechanisms associated with high-salt-mediated vascular endothelial damage. Then, the possible protective mechanism by which endogenous $\mathrm{H}_{2} \mathrm{~S}$ 

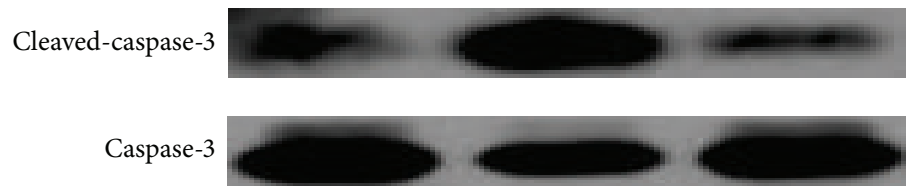

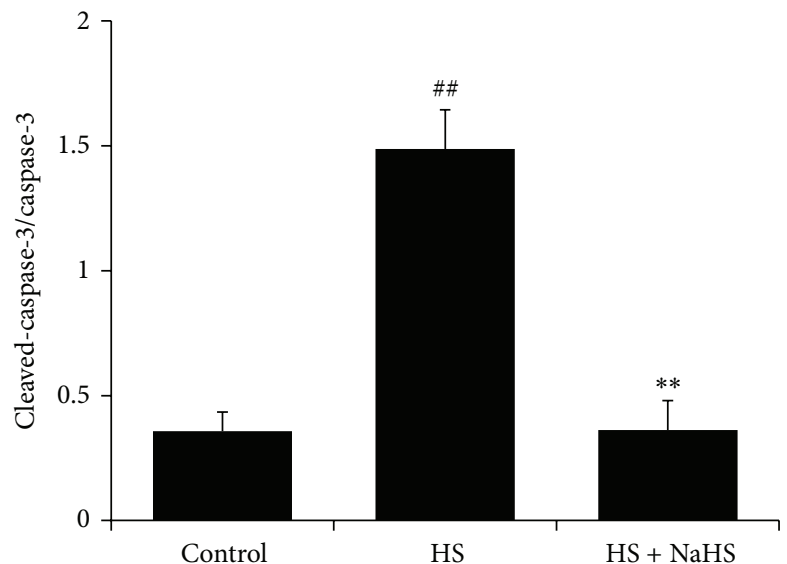

(a)

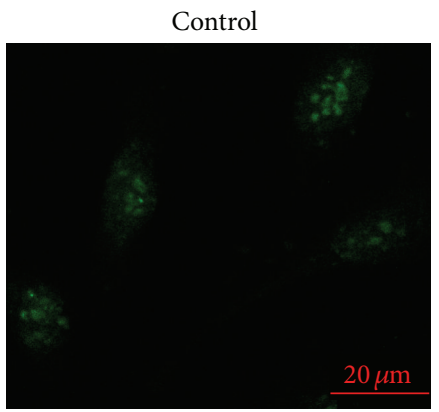

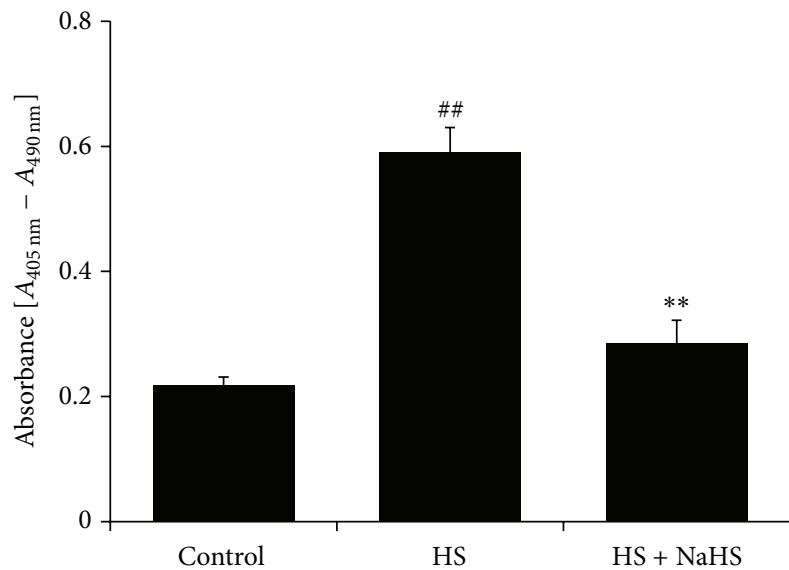

(b)

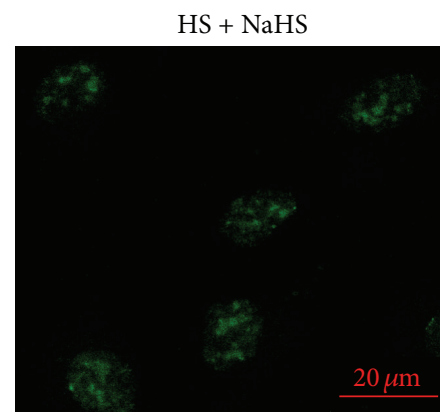

(c)

FIgURE 6: Apoptosis and caspase-3 activities in human umbilical vein endothelial cells (HUVECs). (a) Caspase-3 activities in HUVEC detected by western blot; (b) DNA fragmentation in HUVEC detected by Cell Death Detection ELISA. (c) HUVEC apoptosis detected by in situ Cell Death Detection Kit, Fluorescein. Control: the cell treated with $137 \mathrm{mmol} / \mathrm{L}$ sodium. HS: high salt, the cell treated with $200 \mathrm{mmol} / \mathrm{L}$ sodium for $6 \mathrm{~h}$. HS + NaHS: the cell pretreated with $200 \mu \mathrm{mol} / \mathrm{L} \mathrm{NaHS}$ for $30 \mathrm{~min}$ following $200 \mathrm{mmol} / \mathrm{L}$ sodium for $6 \mathrm{~h}$. ${ }^{\# \#} P<0.01 \mathrm{versus}$ control group; ${ }^{* *} P<0.01$ versus $\mathrm{HS}$ group.

protected against high-salt damage in vascular endothelia was investigated.

Animal experiments revealed that high-salt diet increased production of microvascular reactive oxygen species in rat striated muscles as well as promoted superoxide anion generation in the superior mesenteric arteries, contributing to oxidative stress in vivo $[11,12]$. Other studies established antioxidant effects of $\mathrm{H}_{2} \mathrm{~S}$ in multiple systems of the body including the central nervous system, cardiovascular system, and respiratory system $[19,22,26]$. In the present study, DHE fluorescent probe demonstrated that high-salt stimulation significantly augmented superoxide anion generation in HUVEC. Considering that mitochondrion was one of major sources producing oxygen free radicals, in particular, increased production and decreased removal of oxygen free radicals caused by abnormal mitochondrial structures and dysfunctional mitochondria remain an important mechanism of cellular oxidative stress injury. Therefore, further study was designed to examine oxygen free radical generation in mitochondria using mitochondrial oxygen radical-specific fluorescent probe MitoSOX. The results showed that high salt promoted oxygen free radical generation in mitochondria, which was abolished in the presence of $\mathrm{H}_{2} \mathrm{~S}$. Therefore, we speculate that mitochondria play a crucial role in highsalt-induced vascular endothelial injury and likely mediate protective effects of endogenous $\mathrm{H}_{2} \mathrm{~S}$ on vascular endothelia.

Mitochondria-related apoptosis is one of the important mechanisms for apoptosis [27]. Previous studies showed that excessive generation of mitochondrial ROS might cause lipid peroxidation of mitochondrial membranes, thereby destroying mitochondrial membrane potential and promoting mitochondrial MPTP opening; meanwhile, the combination of cytc and endometrial center phospholipid molecules was broken, releasing the "free" cytc. Increased mitochondrial permeability encouraged the leakage of cytc and other proapoptotic molecules into the cytoplasm, activating caspase- 9 
and caspase-3, initiating apoptosis cascade, and eventually culminating to cell death [28]. Our results showed that, under high-salt treatment, mitochondrial membrane potential in vascular endothelia was significantly reduced along with increased MPTP opening and release of mitochondrial cytc to cytoplasm, activating cytoplasmic caspase-9. In contrast, $\mathrm{H}_{2} \mathrm{~S}$ donor restored mitochondrial membrane potential in vascular endothelia, inhibited MPTP opening, and blocked the leakage of mitochondrial cytc, establishing that $\mathrm{H}_{2} \mathrm{~S}$ antagonized the mitochondria-mediated apoptosis induced by high salt.

Taken together, this study demonstrated for the first time that high salt damaged vascular endothelial cells through downregulating $\mathrm{H}_{2} \mathrm{~S} / \mathrm{CSE}$ pathway, which might subsequently result in augmented endothelial cell oxidative stress, increasing mitochondria-mediated endothelial cell apoptosis.

The limitation of this study was the relatively high dose of sodium used in the experiment. Although recent study showed that HUVECs adapted sodium well at $380 \mathrm{mosmol} /$ $\mathrm{kg}$ (or $190 \mathrm{mmol} / \mathrm{L}$ sodium), maintaining a normal appearance of the cells and a logarithmic growth for two weeks [25], and the concentration of $500 \mathrm{mosmol} / \mathrm{kg}$ (or $250 \mathrm{mmol} / \mathrm{L}$ sodium) was used in the in vitro experiment [29], there was a limited elevation of plasma sodium concentration (about 2-6 $\mathrm{mmol} / \mathrm{L}$ ) in salt-sensitive hypertensive patients and animal models with high-salt diet [30, 31]. Moreover, extreme hypernatraemia $(196 \mathrm{mmol} / \mathrm{L})$ only occurred in a small part of patients [32]. Furthermore, sodium concentration at $150 \mathrm{mmoL}$ and above is very likely to affect the membrane potential of various cells and tertiary protein structure of multiple enzymes and accordingly the enzyme activity, which might interrupt the specificity of the protection of endogenous $\mathrm{H}_{2} \mathrm{~S} / \mathrm{CSE}$ pathway on the HUVECs. Therefore, the effect of a reasonable high-salt insult which was in accordance with clinical change in plasma sodium in the patients and animal model with high-salt diet on the HUVEC needs further investigation.

\section{Conflict of Interests}

The authors declare that there is no conflict of interests regarding the publication of this paper.

\section{Authors' Contribution}

Yanfang Zong and Yaqian Huang contributed equally to this work.

\section{Acknowledgments}

This work was supported by the Major Basic Research Development Program of China (2012CB517806, 2013CB933801, and 2011CB503904), National Natural Science Foundation of China (31130030, 81370154, and 81121061), Grant of Ministry of Education, China (20130001120047), Program for New Century Excellent Talent of Ministry of Education of China (NCET-11-0005), and the Open Project of Key Laboratory of Remodeling-Related Cardiovascular Diseases, Ministry of Education (2014XXGB02).

\section{References}

[1] A. W. Cowley and R. E. McCaa, "Acute and chronic doseresponse relationships for angiotensin, aldosterone, and arterial pressure at varying levels of sodium intake," Circulation Research, vol. 39, no. 6, pp. 788-797, 1976.

[2] K. Ando and T. Fujita, "Pathophysiology of salt sensitivity hypertension," Annals of Medicine, vol. 44, no. 1, pp. S119-S126, 2012.

[3] F. H. H. Leenen, "The central role of the brain aldosterone'ouabain' pathway in salt-sensitive hypertension," Biochimica et Biophysica Acta-Molecular Basis of Disease, vol. 1802, no. 12, pp. 1132-1139, 2010.

[4] A. MacHnik, W. Neuhofer, J. Jantsch et al., "Macrophages regulate salt-dependent volume and blood pressure by a vascular endothelial growth factor-C-dependent buffering mechanism," Nature Medicine, vol. 15, no. 5, pp. 545-552, 2009.

[5] R. D. Wainford, C. Y. Carmichael, C. L. Pascale, and J. T. Kuwabara, "G $\alpha \mathrm{i}_{2}$-protein-mediated signal transduction: central nervous system molecular mechanism countering the development of sodium-dependent hypertension," Hypertension, vol. 65, no. 1, pp. 178-186, 2014.

[6] G. M. Rubanyi, "The role of endothelium in cardiovascular homeostasis and diseases," Journal of Cardiovascular Pharmacology, vol. 22, no. 4, pp. S1-S14, 1993.

[7] M. Mudau, A. Genis, A. Lochner, and H. Strijdom, "Endothelial dysfunction: the early predictor of atherosclerosis," Cardiovascular Journal of Africa, vol. 23, no. 4, pp. 222-231, 2012.

[8] A. Miyoshi, H. Suzuki, M. Fujiwara, M. Masai, and T. Iwasaki, "Impairment of endothelial function in salt-sensitive hypertension in humans," The American Journal of Hypertension, vol. 10, no. 10, pp. 1083-1090, 1997.

[9] M. Paar, H. Pavenstädt, K. Kusche-Vihrog, V. Drüppel, H. Oberleithner, and K. Kliche, "Endothelial sodium channels trigger endothelial salt sensitivity with aging," Hypertension, vol. 64, no. 2, pp. 391-396, 2014.

[10] Y. Qin, G. Xu, J. Fan, R. E. Witt, and C. Da, "High-salt loading exacerbates increased retinal content of aquaporins AQP1 and AQP4 in rats with diabetic retinopathy," Experimental Eye Research, vol. 89, no. 5, pp. 741-747, 2009.

[11] D. M. Lenda, B. A. Sauls, and M. A. Boegehold, "Reactive oxygen species may contribute to reduced endotheliumdependent dilation in rats fed high salt," The American Journal of Physiology: Heart and Circulatory Physiology, vol. 279, no. 1, pp. H7-H14, 2000.

[12] J. Zhu, T. Huang, and J. H. Lombard, "Effect of high-salt diet on vascular relaxation and oxidative stress in mesenteric resistance arteries," Journal of Vascular Research, vol. 44, no. 5, pp. 382390, 2007.

[13] R. Wang, "Two's company, three's a crowd: can $\mathrm{H}_{2} \mathrm{~S}$ be the third endogenous gaseous transmitter?" The FASEB Journal, vol. 16, no. 13, pp. 1792-1798, 2002.

[14] T. T. Pan, Z. N. Feng, S. W. Lee, P. K. Moore, and J. S. Bian, "Endogenous hydrogen sulfide contributes to the cardioprotection by metabolic inhibition preconditioning in the rat ventricular myocytes," Journal of Molecular and Cellular Cardiology, vol. 40, no. 1, pp. 119-130, 2006. 
[15] Y.-H. Liu, M. Lu, Z.-Z. Xie et al., "Hydrogen sulfide prevents heart failure development via inhibition of renin release from mast cells in isoproterenol-treated rats," Antioxidants and Redox Signaling, vol. 20, no. 5, pp. 759-769, 2014.

[16] G. Yang, K. Zhao, Y. Ju et al., "Hydrogen sulfide protects against cellular senescence via S-sulfhydration of keap1 and activation of Nrf2," Antioxidants and Redox Signaling, vol. 18, no. 15, pp. 1906-1919, 2013.

[17] G. Yang, L. Wu, S. Bryan, N. Khaper, S. Mani, and R. Wang, "Cystathionine gamma-lyase deficiency and overproliferation of smooth muscle cells," Cardiovascular Research, vol. 86, no. 3, pp. 487-495, 2010.

[18] Y. Nagai, M. Tsugane, J.-I. Oka, and H. Kimura, "Hydrogen sulfide induces calcium waves in astrocytes," The FASEB Journal, vol. 18, no. 3, pp. 557-559, 2004.

[19] Y. Kimura and H. Kimura, "Hydrogen sulfide protects neurons from oxidative stress," The FASEB Journal, vol. 18, no. 10, pp. 1165-1167, 2004.

[20] G. Yang, L. Wu, B. Jiang et al., " $\mathrm{H}_{2} \mathrm{~S}$ as a physiologic vasorelaxant: hypertension in mice with deletion of cystathionine $\gamma$ lyase," Science, vol. 322, no. 5901, pp. 587-590, 2008.

[21] X. Zhao, L. K. Zhang, C. Y. Zhang et al., "Regulatory effect of hydrogen sulfide on vascular collagen content in spontaneously hypertensive rats," Hypertension Research, vol. 31, no. 8, pp. 1619-1630, 2008.

[22] Y. Shen, W. Guo, Z. Wang, Y. Zhang, L. Zhong, and Y. Zhu, "Protective effects of hydrogen sulfide in hypoxic human umbilical vein endothelial cells: a possible mitochondria-dependent pathway," International Journal of Molecular Sciences, vol. 14, no. 7, pp. 13093-13108, 2013.

[23] B. Chen, W. Li, C. Lv et al., "Fluorescent probe for highly selective and sensitive detection of hydrogen sulfide in living cells and cardiac tissues," Analyst, vol. 138, no. 3, pp. 946-951, 2013.

[24] G. Liu, H. Hitomi, A. Rahman et al., "High sodium augments angiotensin II-induced vascular smooth muscle cell proliferation through the ERK 1/2-dependent pathway," Hypertension Research, vol. 37, no. 1, pp. 13-18, 2014.

[25] N. I. Dmitrieva and M. B. Burg, "Secretion of von Willebrand factor by endothelial cells links sodium to hypercoagulability and thrombosis," Proceedings of the National Academy of Sciences of the United States of America, vol. 111, no. 17, pp. 64856490, 2014.

[26] P. Zhang, F. Li, C. H. Wiegman et al., "Inhibitory effect of hydrogen sulfide on ozone-induced airway inflammation, oxidative stress, and bronchial hyperresponsiveness," American Journal of Respiratory Cell and Molecular Biology, vol. 52, no. 1, pp. 129-137, 2015.

[27] J. Lindsay, M. D. Esposti, and A. P. Gilmore, "Bcl-2 proteins and mitochondria-specificity in membrane targeting for death," Biochimica et Biophysica Acta, vol. 1813, no. 4, pp. 532-539, 2011.

[28] J. M. Adams and S. Cory, "Bcl-2-regulated apoptosis: mechanism and therapeutic potential," Current Opinion in Immunology, vol. 19, no. 5, pp. 488-496, 2007.

[29] C. E. Irarrazabal, M. B. Burg, S. G. Ward, and J. D. Ferraris, "Phosphatidylinositol 3-kinase mediates activation of ATM by high $\mathrm{NaCl}$ and by ionizing radiation: role in osmoprotective transcriptional regulation," Proceedings of the National Academy of Sciences of the United States of America, vol. 103, no. 23, pp. 8882-8887, 2006.

[30] M. Ufnal, A. Drapala, M. Sikora, and T. Zera, "Early highsodium solid diet does not affect sodium intake, sodium preference, blood volume and blood pressure in adult WistarKyoto rats," British Journal of Nutrition, vol. 106, no. 2, pp. 292296, 2011.

[31] O. Schmidlin, A. Forman, A. Sebastian, and R. C. Morris Jr., "Sodium-selective salt sensitivity: its occurrence in blacks," Hypertension, vol. 50, no. 6, pp. 1085-1092, 2007.

[32] J. Jeffery, R. M. Ayling, and R. J. S. McGonigle, "Successful rescue of severe hypernatraemia $(196 \mathrm{mmol} / \mathrm{L})$ by treatment with hypotonic fluid," Annals of Clinical Biochemistry, vol. 44, no. 5, pp. 491-494, 2007. 


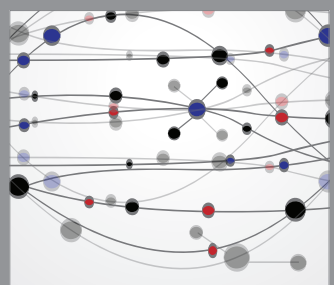

The Scientific World Journal
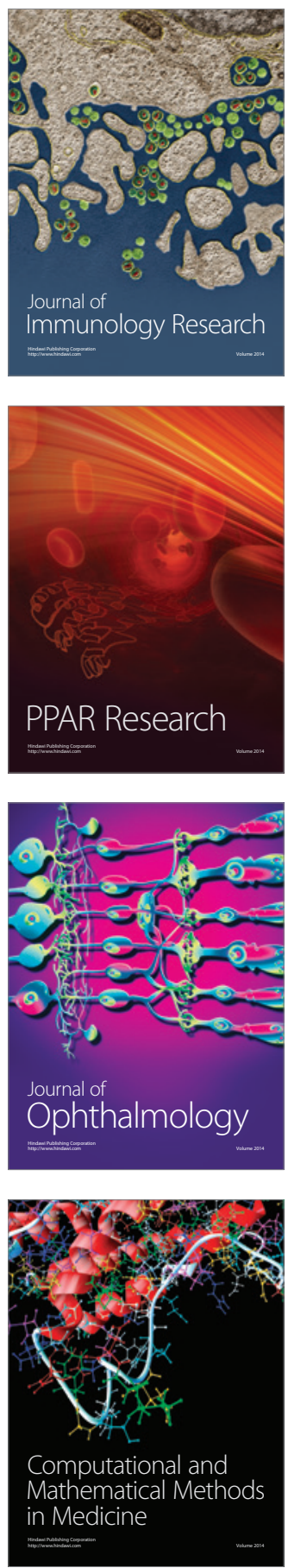

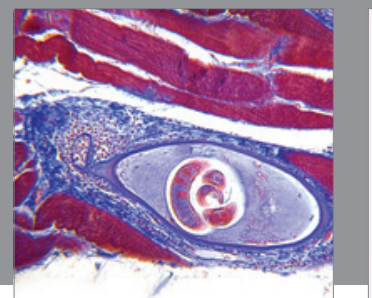

Gastroenterology

Research and Practice
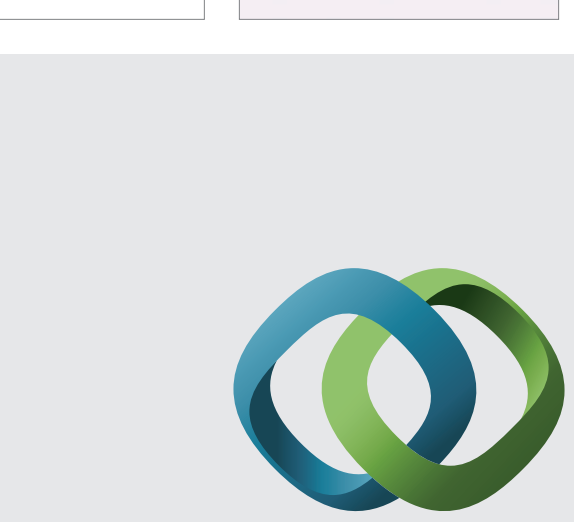

\section{Hindawi}

Submit your manuscripts at

http://www.hindawi.com
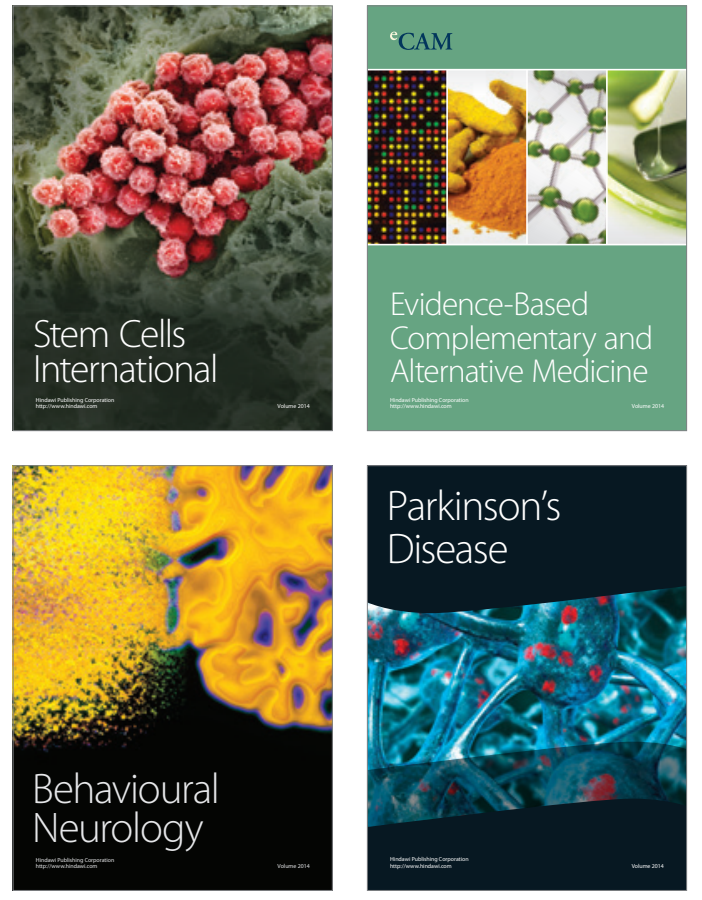
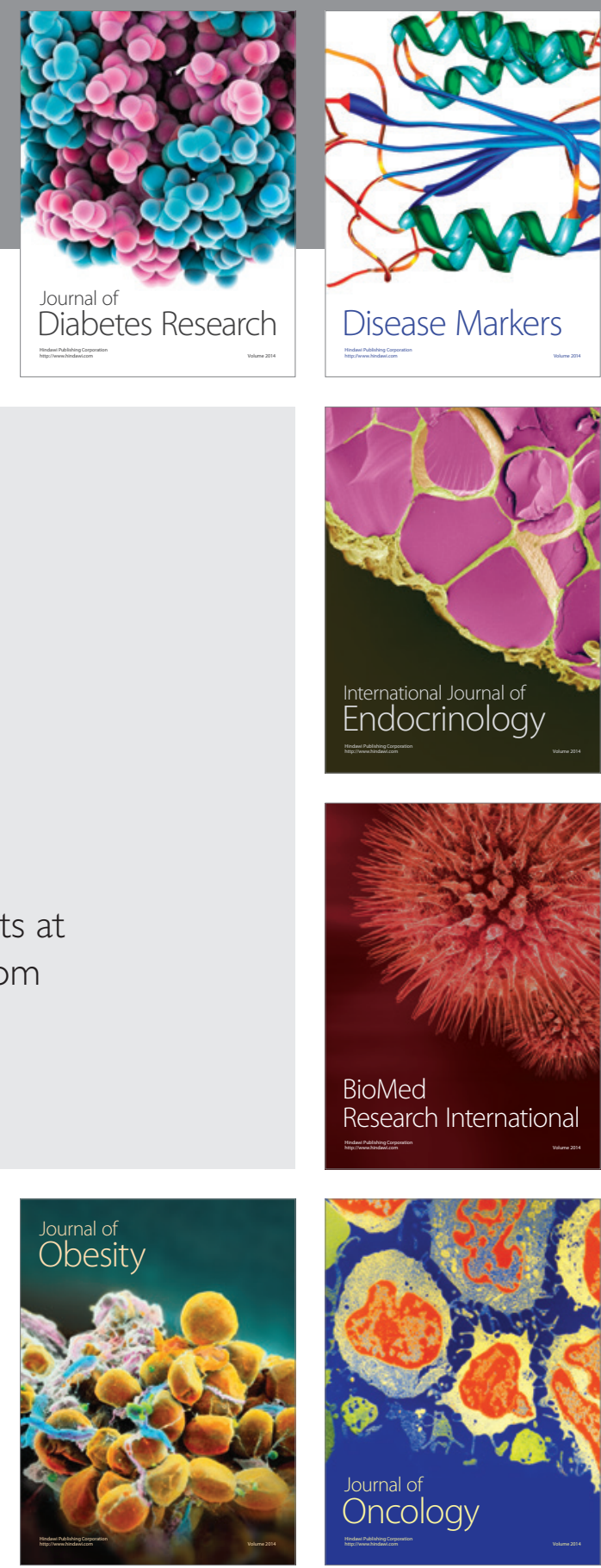

Disease Markers
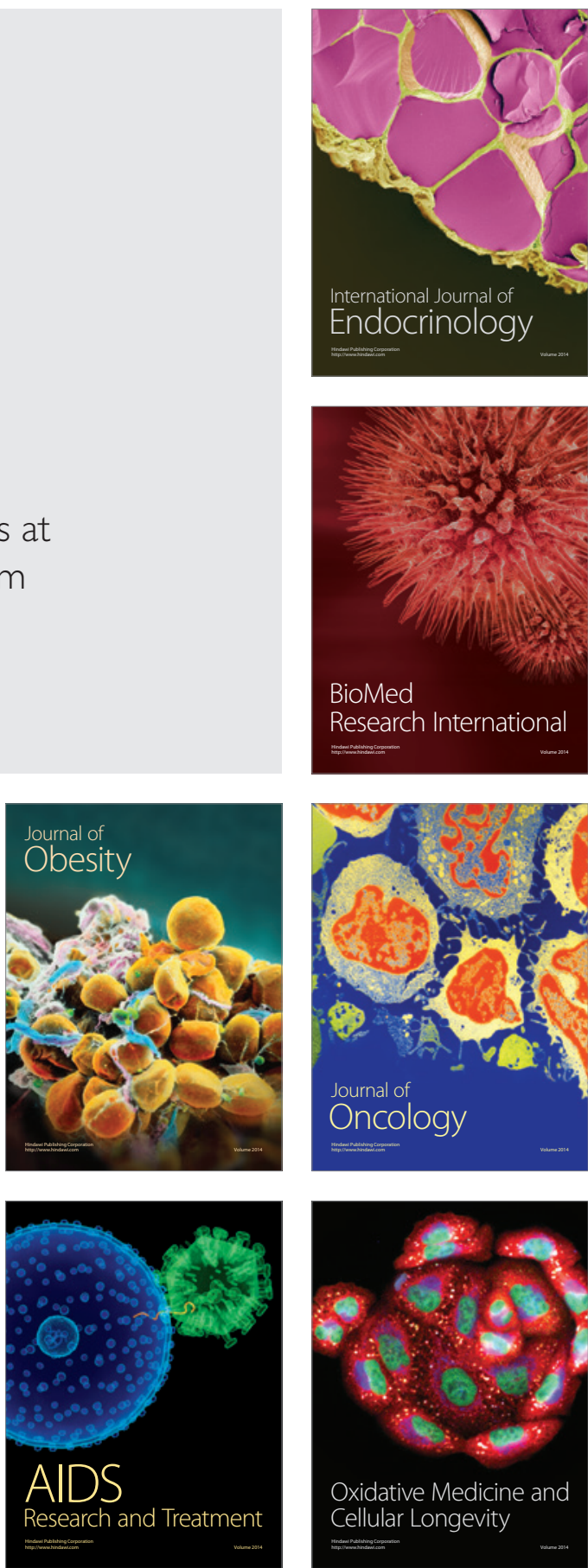